\title{
Hipertermia e exercício físico
}

\author{
Exercise Heatstroke
}

\section{Victor AF Tarini ${ }^{1}$, LigiaVilas $^{2}$, Ricardo Z Pereira ${ }^{3}$, Acary SB Oliveira ${ }^{4}$}

Trabalho realizado no Setor de Doenças Neuromusculares da Universidade Federal de São Paulo - UNIFESP. São Paulo, SP - Brasil.

1.Professor de Educação Física, Mestre em Fisiologia do Exercício; 2.Fisioterapeuta;3.Professor de Educação Física, Mestre em Fisiologia Humana; 4. Médico, Doutor em Neurologia, Chefe do Setor de Doenças Neuromusculares da UNIFESP.

\section{Epidemiologia, Etiologia, Complicações, Fatores de Risco, Intervenções e Prevenção.}

Semelhante às catástrofes provocadas pela natureza como terremotos e inundações, as ondas de calor geradas pelo aquecimento global também provocam muitas mortes. Em julho de 1995, uma prolongada onda de calor atingiu a cidade de Chicago nos Estados Unidos, matando mais de seiscentas pessoas. Entre os dias doze e vinte de julho, a temperatura oscilou entre 33 e $40^{\circ} \mathrm{C}$, atingindo no dia treze um pico de $48^{\circ} \mathrm{C}$.

Entre os meses de agosto e setembro de 2003, cerca de quinze mil pessoas morreram na França em decorrência de uma forte onda de calor sobre uma região despreparada, pois o serviço médico estava bastante reduzido em função do período de férias. Ao longo de vinte e um dias a temperatura atingiu picos de $40^{\circ} \mathrm{C}$.

Em novembro passado, durante a terceira etapa de uma competição de Montain Bike dentro do Parque Nacional da Serra da Capivara (PI), uma competidora sentiu-se mal após percorrer parte do trajeto sob sol forte a uma temperatura de aproximadamente $42^{\circ} \mathrm{C}$. Tendo sido encontrada inconsciente e com a respiração dificultada, foi levada às pressas para um hospital local, aonde chegou em estado de coma profundo, sendo então transferida mais tarde para um hospital em Teresina. A ciclista não resistiu e faleceu durante o trajeto. O médico do hospital de Teresina acredita que a ciclista morreu por hipertermia.

A hipertermia pode se definida como a temperatura corporal central superior a $40^{\circ} \mathrm{C}$, acompanhada de alterações no estado mental, bem como o comprometimento de múltiplos órgãos. Contudo, o aumento da temperatura corporal central acima do ponto de ajuste hipotalâmico $\left(37^{\circ} \mathrm{C}\right)$ já provoca sinais de desconforto.

De modo geral, a hipertermia se apresenta sob duas formas: a clássica (HC), que geralmente atinge crianças e idosos por exposição prolongada a ambientes com temperaturas 
elevadas. É caracterizada por uma falha dos mecanismos responsáveis pela regulação térmica. Alguns fatores foram citados como possíveis causadores deste problema: nos idosos, uma sensibilidade modificada dos termorreceptores, diminuição da capacidade das glândulas sudoríparas por alteração da estrutura intrínseca da própria pele e da sua árvore vascular, menor liberação do tônus vasomotor e vasodilatação menos ativa após o início da transpiração. Já nas crianças, observa-se uma taxa de transpiração mais baixa e uma temperatura corporal central mais alta durante a exposição ao calor intenso se comparadas a adolescentes e adultos apesar de possuírem maior número de glândulas sudoríparas ativadas pelo calor por unidade de área cutânea.

A outra forma de manifestação da hipertermia é a induzida por esforça (HIE), que afeta indivíduos fisicamente ativos. Isso é devido a um aumento na temperatura interna pela atividade prolongada da musculatura, somada a temperatura ambiente e umidade elevadas.

Em ambos os casos, os sinais e sintomas mais freqüentes são: ansiedade, confusão mental, comportamento bizarro, perda de coordenação, alucinações, agitação, apreensão e muitas vezes coma. A estes sinais, soma-se a disfunção de vários órgãos como insuficiência renal aguda, insuficiência hepática, lesão cerebral, insuficiência respiratória, lesão intestinal isquêmica, pancreatite, hemorragia gastrointestinal, trombocitopenia e coagulação.

\section{Etiologia do estresse térmico e da hipertermia}

Parece haver um provável polimorfismo genético que determina a suscetibilidade de desenvolver a hipertermia. Este polimorfismo parece afetar os genes que regulam a atividade das citocinas, proteínas de coagulação e uma série de outras proteínas envolvidas no processo de adaptação ao calor.

\section{Resposta em fase aguda}

A resposta em fase aguda é uma reação coordenada que envolve células endoteliais, leucócitos e células epiteliais que atuam na proteção dos tecidos corporais, bem como no reparo de um dano que eventualmente ocorra. As interleucinas mediam a resposta inflamatória sistêmica. Primeiramente, as interleucinas-1 e 6 estão envolvidas no controle do volume de produção de citocinas em resposta ao aumento de temperatura. A interleucina-6 estimula o fígado a produzir proteínas antiinflamatórias de fase aguda que irão inibir as espécies reativas de oxigênio além de liberarem enzimas proteolíticas. $O$ aumento na quantidade de citocinas semelhantes aos fatores de necrose tumoral alfa, é necessário para 
mediar a febre, promover a leucocitose, sintetizar as proteínas de fase aguda e prevenir o catablismo muscular.

A etapa seguinte, envolve a produção de proteínas de choque térmico. São proteínas resistentes ao calor, sua produção é controlada pela transcrição do gene no DNA dos cromossomos. As proteínas de choque térmico 72 são as primeiras que acumulam no cérebro, promovendo um estado transitório de tolerância ao estresse térmico. Este mecanismo protege o corpo da hipertermia, hipotensão arterial e isquemia cerebral. Este parece ser o mecanismo principal num processo de aclimatação.

Quando a síntese das proteínas de choque térmico é bloqueada ou alterada em função de um polimorfismo na transcrição gênica ou ainda pela ação de anticorpos, as células se tornam extremamente sensíveis ao estresse térmico. Por esta razão, alguns indivíduos podem ser geneticamente propensos a desenvolver síndromes de estresse térmico e até mesmo hipertermia em função da inabilidade de seu organismo de se proteger por meio da produção das proteínas de choque térmico.

\section{Resposta em fase aguda exagerada}

Durante o exercício extenuante ou em situação de hipertermia, o fluxo sangüíneo é desviado da circulação mesentérica para os músculos ativos e para a pele, ocasionando uma isquemia intestinal que por sua vez, permite um aumento da permeabilidade intestinal.

A hipotensão esplâncnica altera as funções imunológicas e de barreira do intestino. Esta alteração permite o vazamento de endotoxinas e o aumento na produção de citocinas inflamatórias, que induzirão a ativação de células endoteliais e a eventual liberação de fatores endoteliais vasoativos como o óxido nítrico e a endotelina. Tanto as citocinas pirogênicas quanto os fatores derivados do endotélio podem interferir no mecanismo de termorregulação, pela elevação do ponto de ajuste no qual a sudorese é ativada e por alterarem o tônus vasomotor particularmente da circulação esplâncnica, por essa razão precipitando a hipotensão e a hipertermia.

\section{Principais complicações clínicas: coagulação intravascular disseminada}

As lesões nas células endoteliais e a trombose microvascular são características proeminentes da hipertermia.

\section{Insuficiência renal aguada}


A insuficiência renal aguda apresenta uma incidência de aproximadamente $30 \%$ em indivíduos com HIE e de 50\% nos casos de HC. Esta disfunção renal pode afetar o parênquima ou os túbulos renais.

\section{Rabdomiólise}

É a lise do tecido muscular esquelético de natureza aguda, com conseqüente liberação dos constituintes celulares (mioglobina, creatinoquinase e mediadores inflamatórios), para o plasma. A mioglobina circulante é filtrada pelos rins e eliminada pela urina (mioglobinúria), o que precipita uma obstrução tubular renal e portanto, insuficiência renal aguda.

\section{Alterações cardiovasculares}

Arritmias bem como hipotensão são característicos neste mal, sendo a hipotensão, o produto da transferência do sangue da circulação central para os tecidos periféricos na tentativa de eliminar calor.

\section{Alterações neurológicas}

As alterações neurológicas são características marcantes na hipertermia. Geralmente podem variar em grau de comprometimento, bem como em duração. Estas alterações incluem delírios, letargia, apreensões e coma.

\section{Fatores de risco para o desenvolvimento das Síndromes induzidas por calor: Desidratação}

Transpiração excessiva, ingestão inadequada de líquidos, vômito, diarréia, bem como o uso de alguns medicamentos, álcool ou cafeína podem promover a perda de fluídos.

\section{Obesidade}

Indivíduos obesos apresentam maior risco de desenvolverem síndromes induzidas por calor, devido a maior espessura do tecido adiposo que dificulta a perda de calor.

\section{Baixa aptidão física}

Indivíduos sedentários ou sem ritmo de treinamento são mais propensos a desenvolverem síndromes induzidas por calor do que indivíduos treinados. 


\section{Vestimenta inadequada}

O excesso de roupas ou trajes inadequados para a prática de atividades físicas no calor intenso compromete a habilidade do sistema termorregulatório. Roupas de cores escuras aumentam a absorção de calor do ambiente, o que promove aumento da temperatura corporal.

\section{Falta de aclimatação ao calor}

\section{Drogas}

O abuso de drogas em casas noturnas constantemente faz vítimas por todo o mundo. Tanto que uma organização norte-americana criou uma página na Web a www.dancesafe.org, dedicada a promover saúde e segurança entre a comunidade de frequentadores de festas Raves e danceterias. Em um levantamento publicado neste site, mais de 100 pessoas morreram após tomar "ecstasy" (3,4 metilenodioximetanfetamina) em festas Raves.

Algumas medicações também podem aumentar os riscos de desenvolver síndromes induzidas por calor, quando associadas a exercícios em dias quentes são elas: betabloqueadores, diuréticos, anticolinérgicos, antidepressivos, antipsicóticos, toxinas naturais, estricnina, agentes simpatomiméticos e anoréticos, hormônios tireóideos e ruptores da fosforilação oxidativa.

\section{Doenças}

As doenças das vias aéreas superiores comprometem muito a eliminação do calor podendo aumentar os riscos.

\section{Ambiente}

Quando a temperatura externa supera a temperatura da pele, o corpo começa a absorver o calor do ambiente e passa a depender totalmente da evaporação da transpiração para eliminar o calor. Para que a transpiração evapore, é necessário que haja um gradiente favorável. A alta umidade relativa do ar compromete este gradiente inibindo a evaporação. Os fatores ambientais que influenciam o risco para as síndromes induzidas por calor incluem a temperatura ambiente, umidade relativa (quantidade de vapor d'água no ar), movimento do ar e a quantidade de calor radiante vindo do sol e de outras fontes.

\section{Intervenções}


A plena compreensão das alterações fisiopatológicas que ocorrem ao longo de um continuum da síndrome hipertermia é fundamental para os cuidados imediatos e adequados, na tentava de minimizar os danos ao organismo.

As principais medidas combinam bases ressuscitativas com resfriamento intenso, objetivando reduzir a temperatura corporal. O monitoramento da temperatura retal e ou esofágea deve ser constante, o que permite acompanhar a evolução do quadro.

As medidas de resfriamento devem ser interrompidas quando a temperatura corporal atingir 38 a $38,5^{\circ} \mathrm{C}$, para evitar uma reversão hipotérmica. A redução da temperatura corporal central abaixo de $38,9^{\circ} \mathrm{C}$ nos trinta primeiros minutos, aumenta a chance de sobrevivência e minimiza os danos aos órgãos. $\mathrm{O}$ ideal seria reduzir a temperatura corporal central em $0,2^{\circ} \mathrm{C}$ por minuto. Infelizmente, há indícios de que os danos aos tecidos podem continuar ocorrendo mesmo depois de se atingir este objetivo em $25 \%$ dos casos. A tabela 3 sumariza os métodos de resfriamento.

Uma medida farmacológica que tem sido discutida com freqüência em muitos estudos é o uso de Dantrolene na tentativa de frear o aumento de temperatura na síndrome de HIE. Dantrolene é um relaxante muscular que diminui a quantidade de $\mathrm{Ca}^{2}$ liberada pelo retículo sarcolasmático para o citosol. Como resultado a atividade muscular é deprimida, diminuindo assim o calor produzido pelo corpo. Apesar de ser bastante eficiente no tratamento da hipertermia maligna, sua eficiência no tratamento de HIE é controversa. Até o presente momento não há evidências suficientes para recomendar que esta droga seja usada rotineiramente no tratamento de HIE.

\section{Prevenção}

Alguns documentos já foram elaborados por centros de pesquisas, com recomendações para minimizar os riscos de desenvolvimento das síndromes induzidas por calor.

É possível prevenir tanto a HC quanto a forma induzida pelo exercício. No caso da forma clássica, é fundamental que uma atenção especial seja dada a crianças recém-nascidas, pré-adolescentes, bem como a indivíduos com idades superiores a 65 anos. Os informes meteorológicos podem salvar vidas. Portanto, é fundamental que seus responsáveis estejam alerta durante os períodos de calor mais frequente, com o intuito de evitar uma exposição arriscada.

A redução dos riscos relativos a HIE requer em primeiro lugar aclimatação por parte daqueles que pretendem participar de competições em ambientes quentes. Esta aclimatação 
consiste de sessões de treinamento sob o sol forte a intensidades de esforço moderadas porém progressivas, de modo que as adaptações fisiológicas aconteçam de forma segura. A ativação precoce do eixo renina angiotensina aldosterona, promove maior conservação de sódio por parte das glândulas sudoríparas e dos rins. Um aumento na conservação de sódio gera um maior volume plasmático, um aumento na taxa de filtração glomerular e uma maior resistência a rabdomiólise.

Em termos gerais a hidratação exerce um papel fundamental na prevenção relativa às síndromes induzidas por calor. A reposição dos líquidos deve concentrar-se na manutenção do volume plasmático, para que a circulação e a transpiração possam progredir em níveis ótimos. A ingestão de uma quantidade extra de líquidos antes das atividades físicas no calor, pode proporcionar uma pequena proteção termorreguladora.

Tabela 01. Síndromes induzidas por calor.

\begin{tabular}{|c|c|c|c|}
\hline Síndromes & Sintomas & Sinais & Tratamento \\
\hline Edema por calor & Não há & Edema periférico & $\begin{array}{l}\text { Descanso, elevação } \\
\text { Das extremidades } \\
\text { aclimatação }\end{array}$ \\
\hline $\begin{array}{l}\text { Contraturas por } \\
\text { calor }\end{array}$ & $\begin{array}{l}\text { Contraturas e dores } \\
\text { musculares }\end{array}$ & Espasmos musculares & $\begin{array}{l}\text { Alongamentos, massagem } \\
\text { com gelo e hidratação oral }\end{array}$ \\
\hline Síncope por calor & Síncope & Perda de consciência & $\begin{array}{l}\text { Descanso, deitar com os } \\
\text { pés elevados, monitorar } \\
\text { sinais vitais }\end{array}$ \\
\hline Exaustão por calor & $\begin{array}{l}\text { Fadiga, incapacidade de } \\
\text { continuar exercício, } \\
\text { tonturas, náuseas, vômitos, } \\
\text { síncope, arrepios no } \\
\text { pescoço }\end{array}$ & $\begin{array}{l}\text { Hipotensão, desequilíbrio, } \\
\text { temperatura corp. central } \\
\text { superior a } 40,5^{\circ} \mathrm{C} \text { e } \\
\text { síncope }\end{array}$ & $\begin{array}{l}\text { Vias aéreas respiração e } \\
\text { circulação, resfriar, } \\
\text { descanso, monitoramento } \\
\text { da temperatura, sinais } \\
\text { vitais e fluidos orais }\end{array}$ \\
\hline Hipertermia & $\begin{array}{l}\text { Evidentes mudanças no } \\
\text { estado mental, fadiga, } \\
\text { náuseas, vômitos e síncope }\end{array}$ & $\begin{array}{l}\text { Temperatura corp. central } \\
\text { superior a } 40,5^{\circ} \mathrm{C} \text {, } \\
\text { hipotensão, taquicardia, } \\
\text { taquipinéia, síncope, } \\
\text { possível ausência de } \\
\text { sudorese, coma, } \\
\text { coagulação intravascular } \\
\text { disseminada, insuficiência } \\
\text { renal aguda }\end{array}$ & $\begin{array}{l}\text { Vias aéreas respiração e } \\
\text { circulação, resfriar, } \\
\text { urgentemente, monitorar } \\
\text { sinais vitais, hidratação } \\
\text { intravenosa se possível e } \\
\text { encaminhar urgente à } \\
\text { emergência médica }\end{array}$ \\
\hline
\end{tabular}




\section{Referências}

1. Christianini C. Reportagem sobre a morte da ciclista durante a prova de Montain Bike. 16/11/2004. http://www.cbc.esp.br/inquerito.htm acessado dia 21/05/2005 20:24 hs.

2. Hadad E, Rav-Acha M, Heled Y, Epstein Y, Moran DS. Heat Stroke: a review of cooling methods. Sports Med 2004; 34(8): 501-511.

3. Bouchama A, Knochel JP. Medical progress: Heat Stroke. N Engl J Med 2002; 346(25): 1978-1988.

4. Lee-Chiong Jr TL, Stitt JT. Heat stroke and other heat-related illness: The maladies of summer. Postgrad Med 1995; 98(1): 26-36.

5. McArdle WD, Katch FI, Katch VL. Exercício e estresse térmico. In: McArdle WD, Katch F I, Katch VL. Fisiologia do Exercício: Energia Nutrição e Desempenho humano, $5^{\mathrm{a}}$ Edição. Guanabara Koogan, 2003, 636-667.

7. Jurkat-Rott K, McCarthy T, Lehmann-Horn F. Genetics and pathogenesis of malignant hyperthermia. Muscle and Nerve 2000; 23: 4-17.

8. Vanakoski J, Seppala T. Heat exposure and drugs: a review of the effects of hyperthermia on pharmacokinetics. Clin Pharmacokinetc 1998; 34: 311-322.

9. Brewster SJ, O'Connor FG, Lillegard WA. Exercise-induced heat injury diagnosis and management. Sports Med Arthrosc Rev 1995; 3: 206-266. 